\title{
Mechanical Properties and Acoustic Emission Characteristics of Thawing Frozen Sandstone
}

\author{
Gengshe Yang, ${ }^{1}$ Bo Liang $\left(\mathbb{D},{ }^{1}\right.$ Hui Liu, ${ }^{1}$ Yanjun Shen, ${ }^{2,3}$ and Hailiang Jia $\mathbb{D}^{1}$ \\ ${ }^{1}$ School of Architecture and Civil Engineering, Xi'an University of Science and Technology, Xi'an, Shaanxi 710054, China \\ ${ }^{2}$ College of Geology and Environment, Xi'an University of Science and Technology, Xi'an, Shaanxi 710054, China \\ ${ }^{3}$ Coal Green Mining Research Institute, Xi'an University of Science and Technology, Xi'an, Shaanxi 710054, China
}

Correspondence should be addressed to Bo Liang; liangbo@xust.edu.cn

Received 21 December 2021; Revised 15 January 2022; Accepted 22 January 2022; Published 22 February 2022

Academic Editor: Paweł Kłosowski

Copyright (c) 2022 Gengshe Yang et al. This is an open access article distributed under the Creative Commons Attribution License, which permits unrestricted use, distribution, and reproduction in any medium, provided the original work is properly cited.

\begin{abstract}
After the construction of a frozen shaft wall is completed, it undergoes a long thawing process. Damage accumulation under load may result in the rupture of the frozen wall and cause engineering accidents. The change in the mechanical properties of the frozen rock during the thawing process is crucial to the stability of the frozen wall. In this study, we selected Cretaceous saturated sandstone as the research object and performed uniaxial compression tests on the frozen sandstone to analyze its mechanical properties during the thawing process. In addition, acoustic emission technology was used to analyze the damage and failure characteristics of the rock. The main findings of the study are as follows: (1) the results of the uniaxial compression tests revealed that the thawing of frozen sandstone comprises five stages. The closure stress, crack initiation stress, expansion strength, and peak strength were obtained from the volumetric stress-strain curve. These four stress values act as the dividing points of the five stages. (2) The initiation stress of frozen sandstone at different temperatures accounts for approximately $50 \%$ of the peak strength. The strength value is low, the deformation is large, and it exhibits an obvious strain-softening phenomenon. (3) As the temperature increases, the closure level of the saturated sandstone gradually increases, and the crack initiation and expansion levels gradually decrease. (4) Based on the four characteristic stresses of the thawing process of frozen sandstone, the acoustic emission signal can be divided into a quiet period, an increasing period, a frequent period, a sharp increase period, and a decline period. (5) A frozen sandstone damage model was established based on the D-P failure criterion. The efficacy of the model was evaluated against the test data and was found to be reasonably accurate. This paper uses acoustic emission technology to simultaneously monitor the melting process of frozen rocks and reveal the relationship between intensity and temperature. The results provide theoretical and technical support for evaluating the mechanical damage induced by thawing of a frozen shaft wall.
\end{abstract}

\section{Introduction}

As shallow coal resources have been exhausted, the depth of mine construction has gradually increased. During well construction, it is necessary to traverse deep and thick, water-rich Cretaceous soft rock formations. The artificial freezing method is widely used in well construction as it offers several unique advantages. Numerous scholars have conducted in-depth research on Cretaceous strata, but some serious safety problems still exist in engineering construction [1-4]. In particular, after the excavation of the vertical shaft, the frozen wall remains in a thawing state for a long time. In this state, the rock may deform and become unstable, leading to ultimate failure. Therefore, in-depth research is required on the mechanical properties of rocks during the thawing process.

Various experts and scholars have conducted extensive research on the mechanical properties of rocks at low temperatures and obtained important findings [5-10]. Currently, in-depth research is primarily carried out through a combination of theoretical analyses [11], indoor experiments [12], and numerical simulations [13]. Luo et al. [14] found that freezing and thawing have a significant impact on the deterioration of the mechanical properties of the slope rock mass, which should be considered when determining the parameters of the slope rock mass in the 
cold region. $\mathrm{Mu}$ et al. [15] chose three typical jointed rocks and subjected them to multiple freeze-thaw cycles followed by direct shear tests on the joint samples in the rock material. The change in shear parameters after an increasing number of freeze-thaw cycles was used to test the degradation characteristics of the rock joints. Zhang et al. [16] built a rock damage model that simulates freeze-thaw cycles and loads based on the theory of continuum damage mechanics, considering the influence of the confining pressure and the random characteristics of rock material defects. In order to study the freeze-thaw damage mechanism of the elastic modulus of soil-rock mixtures at different confining pressures, Zhou et al. [17] proposed the concept of mesointerfacial freeze-thaw damage coefficient and concerned the mesointerfacial damage phenomenon of soil-rock mixtures caused by the freeze-thaw cycle environment. Considering the problem of rock freeze-thaw failure, Huang et al. [18] developed the theory of ice crystallization and frost heave under freeze-thaw conditions in an elastoplastic system and proposed a new elastoplastic model to estimate the longterm frost heave and frost damage under freeze-thaw conditions. The model considers the influence of the pore size, matrix yield stress, and water saturation on the development of the pore frost heave pressure. Combined with specific engineering projects, Wang et al. [19] studied the physical parameters and triaxial compression mechanical properties under different freeze-thaw cycles with complete hard rock represented by fine sandstone and coarse sandstone. Based on the results of the triaxial compression test of frozen sandstone, Li et al. [20] established a binary medium constitutive model of frozen red sandstone.

As the mechanical testing of rock is complex and discrete, it is easier to perform simultaneous monitoring through various technical means such as computed tomography (CT) [21, 22], nuclear magnetism [23-24], and acoustic emission (AE) $[25,26]$. Liu et al. [27] used triaxial seepage tests and AE monitoring to study the mechanical and hydraulic properties of argillaceous sandstone samples under a complete freeze-thaw loading cycle. Chen et al. [28] performed triaxial compression tests to analyze the influence of freeze-thaw cycles on sandstone under low confining pressure and determined the damage characteristics of the internal microstructure of the sandstone using $\mathrm{AE}$ and Mercury intrusion porosity measurements. Wang et al. [29] performed multistage compression cyclic loading experiments on rock masses with natural fractures and used realtime AE monitoring and posttest CT scanning to study the fracture evolution of naturally fractured granites. At present, experts and scholars have performed a lot of research on the mechanical properties of rocks at low temperatures and have achieved certain theoretical results. The freezing method is widely used in some special geological environments. After the geotechnical construction is completed, the rock will be in the thawing process for a certain period of time. At this time, the mechanical properties of frozen rocks are equally important, but there are few studies on this aspect.

This study uses the return air shaft of the Xinzhuang coal mine in Gansu as its engineering background. During the shaft excavation process, it is necessary to traverse thick, water-rich, and soft rock layers, and the freezing method is used to form a frozen wall of a certain thickness during construction. After the shaft excavation process is complete, the frozen wall remains in a thawing state for a certain duration. Frozen soft rocks can experience damage accumulation under load. If the rock remains in the thawing state for a long duration, the damage accumulation may cause the frozen wall to rupture; aquifers may then erode the frozen wall, resulting in cementation of the rock and causing a large deformation.

\section{Materials and Methods}

2.1. Sample Preparation. The sandstone used herein was a dark red, water-rich Cretaceous soft rock with well-developed and clear joint planes. The size of the rock samples was $\varnothing 50 \mathrm{~mm} \times 100 \mathrm{~mm}$ (as shown in Figure 1). The processed rock samples were tested using an ultrasonic detection analyzer, and the rock samples near the average value of the longitudinal wave were selected to reduce the errors caused by discrete types of rock in the test results. The basic physical parameters are listed in Table 1.

2.2. Analysis of Mineral Composition. The rock was ground into a powder to analyze its composition. A mineral composition analysis was performed using a Rigaku D/Max 2500 $\mathrm{X}$-ray diffractometer, as shown in Figure 2.

The stability of sandstone is affected by its mineral composition. The composition and structure of sandstone can be roughly divided into three categories: nonclay minerals, clay minerals, and porous media. The nonclay mineral content in the rock sample used herein was more than $90 \%$ of the total composition, whereas the clay mineral content was relatively small. The main components of the nonclay minerals were quartz, plagioclase, and potash feldspar. The chemical composition was relatively stable and was not significantly affected by the environment. In contrast, the clay minerals were affected by the environment. The main mineral components of the sandstone are shown in Table 1.

As shown in Table 1, the mineral composition of the sandstone primarily included quartz, feldspar, mica, calcite, and clay minerals. The clay content was relatively high and was dominated by argillaceous cementation. The clay minerals in the Cretaceous sandstone sample were primarily montmorillonite and chlorite, where $\mathrm{SiO}_{2}$ had the highest chemical composition, with $20.35 \%$ and $12.19 \%$, respectively; the second-highest chemical component was $\mathrm{Al}_{2} \mathrm{O}_{3}$, with $8.72 \%$ and $4.5 \%$, respectively. The particles were cemented together in the form of an inorganic cement, which provides certain strength. When the content of chlorite, which contains $\mathrm{CaCO}_{3}$, is high, the strength of the sandstone increases and the physical properties of water improve. The $\mathrm{Fe}_{2} \mathrm{O}_{3}$ content was $2.25 \%$ and $4.07 \%$, respectively. The red color of the Cretaceous sandstone can be attributed to its high iron content. The total montmorillonite content was $6 \%$. Other oxides provide $\mathrm{Mg}^{2+}, \mathrm{Na}^{+}$, and $\mathrm{K}^{+}$ plasma, which have high physical and chemical activity and 


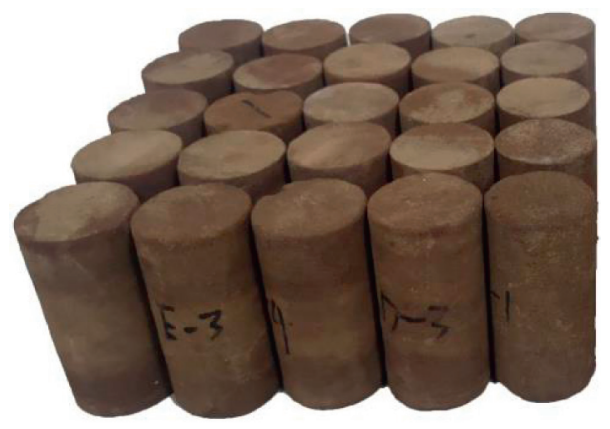

Figure 1: Sandstone samples.

TABLE 1: Sandstone mineral composition.

\begin{tabular}{lcccccccc}
\hline Element & Quartz & Plagioclase & Potash feldspar & Calcite & Dolomite & Chlorite & Montmorillonite & Hematite \\
\hline Content (\%) & 48.9 & 22.9 & 10.7 & 6 & 0.9 & 4 & 6 & 0.6 \\
\hline
\end{tabular}

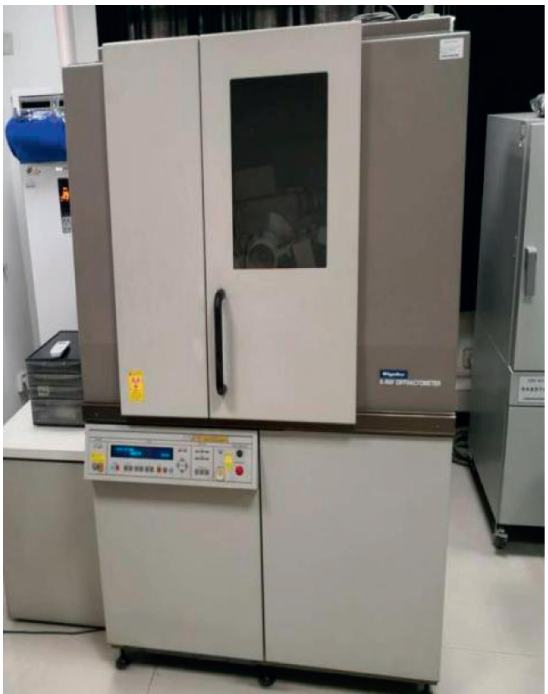

Figure 2: X-ray diffractometer.

hydrophilicity, and have certain impact on the change in the strength of the saturated sandstone. The exchangeable cations were primarily $\mathrm{Ca}^{2+}, \mathrm{Mg}^{2+}, \mathrm{K}^{+}$, and $\mathrm{Na}^{+}$. These ions are adsorbed onto the surface of the particles and increased their hydrophilicity, which decreases the water strength of the sandstone and resulted in a certain degree of disintegration and expansion. It is shown in Figure 3.

2.3. Uniaxial Compression Tests. The prepared sandstone was subjected to uniaxial compression tests to determine the mechanical properties of the saturated sandstone. The tests were performed as follows (Figures 4 and 5):

(1) A prepared standard rock sample was placed in an oven and dried at $105^{\circ} \mathrm{C}$ for $24 \mathrm{~h}$. Subsequently, the sample was placed in a vacuum saturation device and vacuumized for $2 \mathrm{~h}$. After being saturated for $24 \mathrm{~h}$, it was stored in a sealed container.

(2) The prepared saturated sandstone sample was placed in a hoop with a rubber sleeve, and test papers were placed on either end of the test piece.

(3) The sample was placed in the loading system of the electro-hydraulic servo control dynamic geotechnical three-axis test system (GCTS). Four acoustic emission sensors were divided into two layers and distributed symmetrically. The two sensor layers were placed perpendicular to each other and installed at heights of $1 / 5 \mathrm{~h}$ and $4 / 5 \mathrm{~h}$, respectively. The radial displacement sensor was installed at a height of $1 / 2 \mathrm{~h}$, and the axial displacement sensor was installed at the ends, as shown in Figure 4.

(4) A confining oil was poured into the pressure chamber, and the temperature control system was switched on. The pressure chamber was frozen at a low temperature with a temperature reduction rate of $10^{\circ} \mathrm{C} / \mathrm{h}$. Once the room temperature was $-30^{\circ} \mathrm{C}$, the room was maintained at this temperature for $24 \mathrm{~h}$. Subsequently, the temperature control system was used to thaw and maintain the sample at a temperature of $-20^{\circ} \mathrm{C}$.

(5) Axial strain was used as the control variable, and it was applied at a rate of $0.12 \mathrm{~mm} / \mathrm{min}$. The axial load was applied until the specimen broke, and the full stress-strain curve of the specimen was obtained under different conditions.

(6) This procedure was repeated at test temperatures of $-10^{\circ} \mathrm{C},-6^{\circ} \mathrm{C},-4^{\circ} \mathrm{C},-2^{\circ} \mathrm{C}, 0^{\circ} \mathrm{C}$, and $20^{\circ} \mathrm{C}$. The maximum axial loads and stress-strain curves at the time of failure were recorded at each test temperature. The test equipment is shown in Figure 5. 

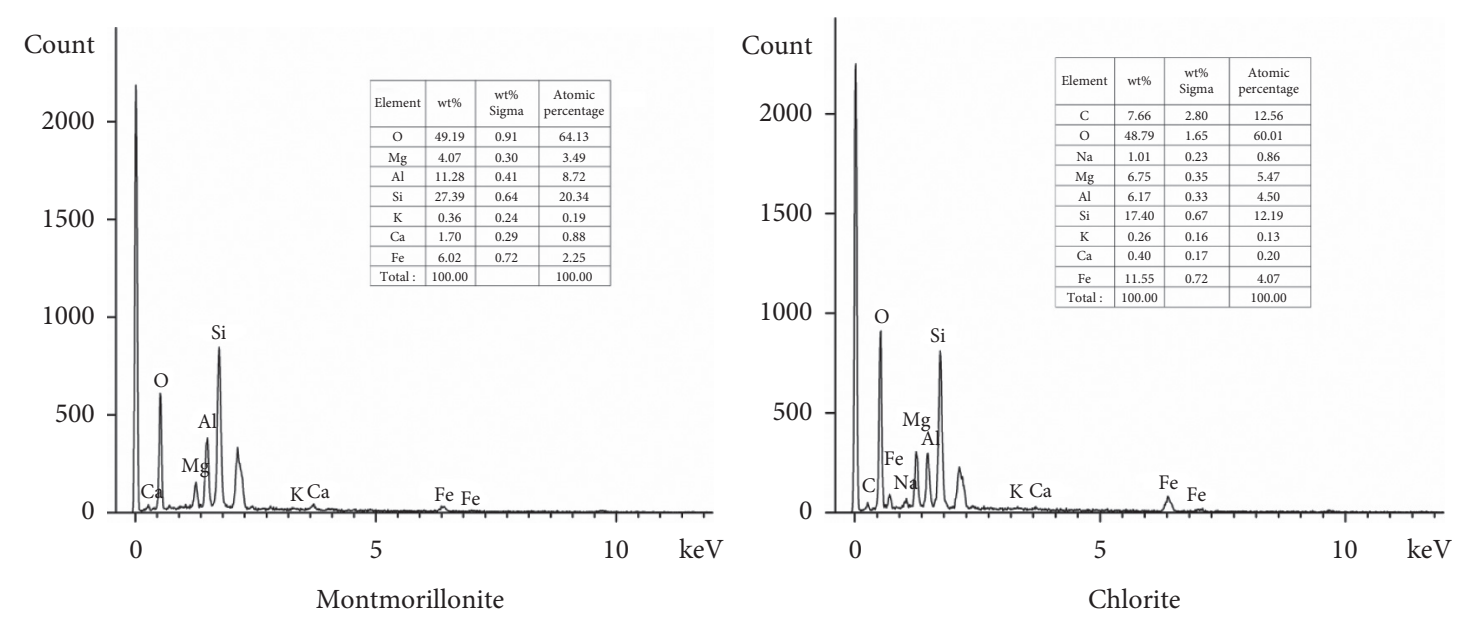

FIGURe 3: Energy spectrum analysis.

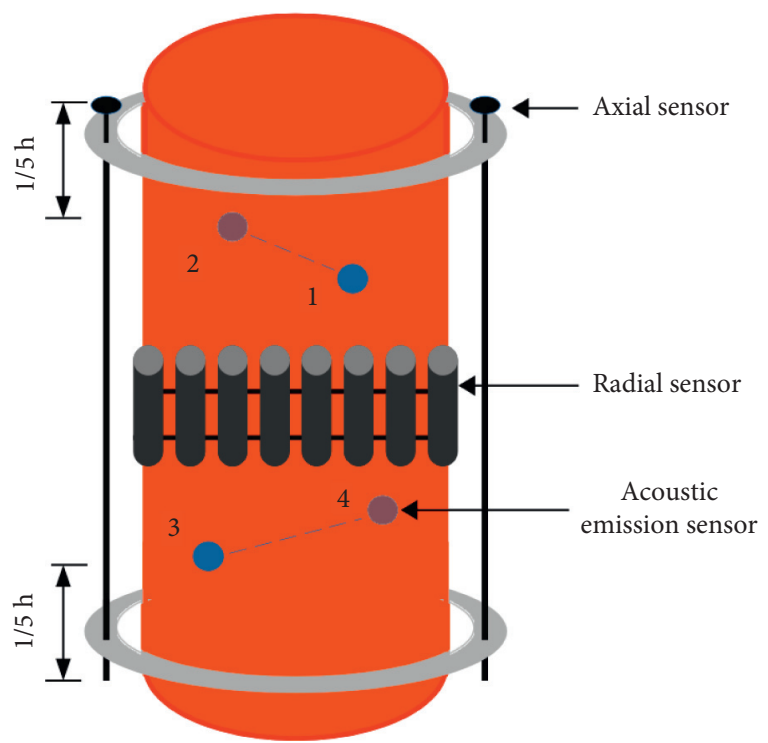

FIgURE 4: Sensor installation on the test piece.

\section{Results and Analysis}

3.1. Uniaxial Compression Tests. The stress-strain curves of the Cretaceous saturated sandstone have common characteristics under different temperature conditions. Each curve can be divided into five stages: the compaction stage, linear elastic stage, crack propagation stage, plastic yield stage, and postpeak stage, as shown in Figure 6. As the temperature increased, the compaction phenomenon became increasingly obvious. As the strain gradually increased, the compaction phase ended. The original cracks began to propagate along with the generation of new cracks, and the cracks propagated stably. During this stage, the curve appears as an approximately straight line. The stress at which the crack starts to grow is called the initiation stress $\left(\sigma_{\mathrm{c}}\right)$. As the load continued to increase, additional pores and cracks developed, especially after the load reached the expansion stress $\left(\sigma_{\mathrm{f}}\right)$. During this stage, the curve had an upward convex shape, the radial strain increased rapidly, and the volumetric strain appeared to reach a turning point. When the load reached its peak stress $\left(\sigma_{\mathrm{s}}\right)$, the curve dropped sharply, and cracks appeared on the surface of the specimen, followed by its failure.

As stated in Section 2, the mineral components of Cretaceous sandstone are primarily quartz, feldspar, calcite, and clay minerals. Clay minerals such as chlorite and montmorillonite undergo a series of dissolutions and ion exchanges under the action of water, which causes the expansion of the pores between the minerals and reduces their bonding capacity. Under the action of an external force, the original cracks in the sandstone begin to propagate, resulting in rock damage.

3.2. Characteristic Stress Analysis of Sandstone at Different Temperatures. Rock damage is primarily caused by the initiation, expansion, and penetration of original and new cracks under the action of an external load. Therefore, during the uniaxial compression tests, in addition to the peak strength $\left(\sigma_{\mathrm{s}}\right)$ of the rock, the crack closure stress $\left(\sigma_{\mathrm{cc}}\right)$, crack initiation stress $\left(\sigma_{\mathrm{ci}}\right)$, and expansion stress $\left(\sigma_{\mathrm{f}}\right)$ of the rock must also be considered. These three stresses can be determined from the crack volume change curve of the rock during the compression test, as shown in Figure 7.

The volumetric strain of the rock is composed of the elastic volumetric strain and the crack volumetric strain produced by internal crack development, as shown in (1):

$$
\varepsilon_{v}=\varepsilon_{v}^{e}+\varepsilon_{v}^{c}
$$

where $\varepsilon_{v}$ is the total volumetric strain of the rock, $\varepsilon_{v}^{e}$ is the elastic volumetric strain of the rock, and $\varepsilon_{\mathrm{v}}^{c}$ is the volumetric strain of the rock cracks.

According to Hooke's law

$$
\left\{\begin{array}{l}
\varepsilon_{v}^{e}=\varepsilon_{1}^{e}+\varepsilon_{2}^{e}+\varepsilon_{3}^{e} \\
\varepsilon_{v}=\varepsilon_{1}+2 \varepsilon_{2}
\end{array}\right.
$$

From (1) and (2), the crack volume strain of the saturated sandstone during the uniaxial compression test is 


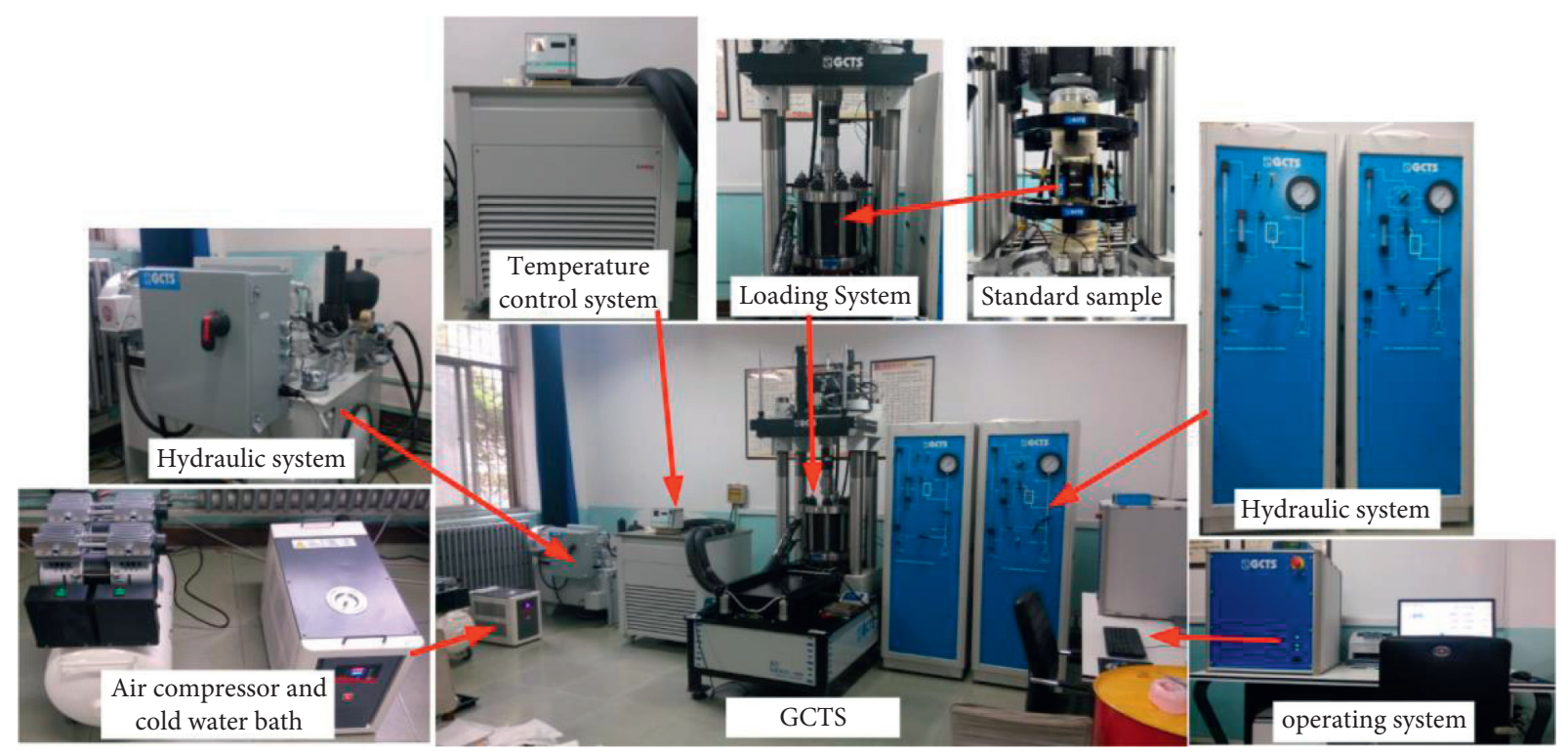

Figure 5: GCTS test system.

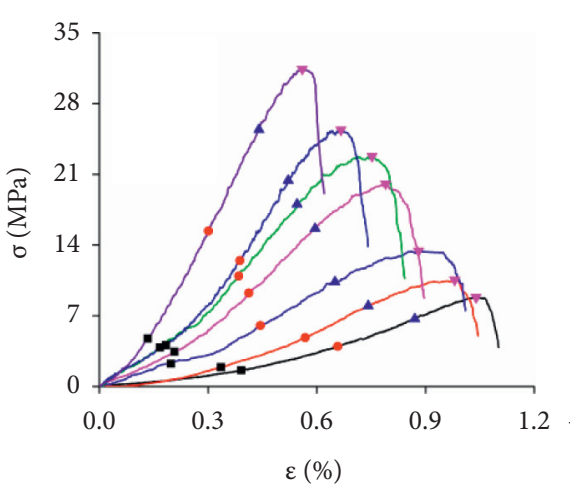

Axial stress-strain curve

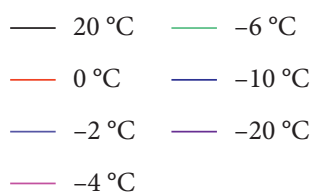

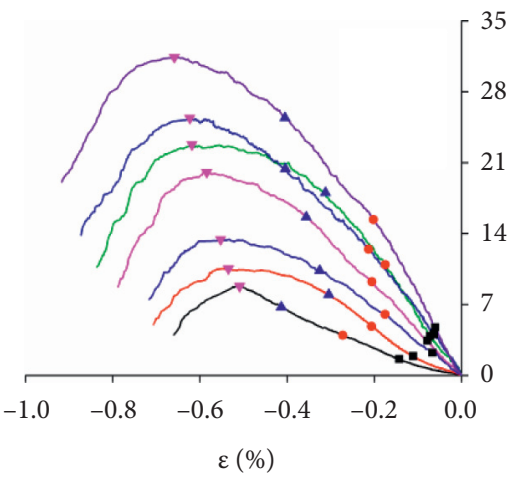

Radial stress-strain curve

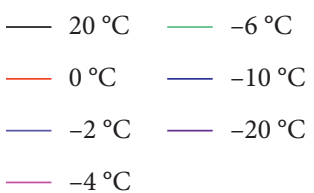

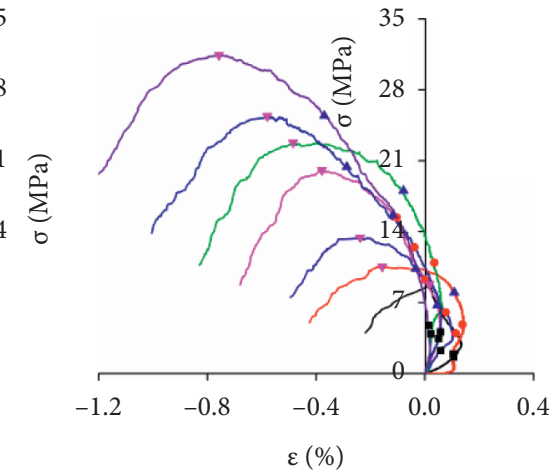

Volumetric stress-strain curve

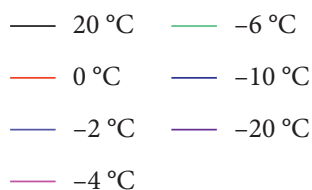

Figure 6: Stress-strain curve of frozen sandstone during thawing.

$$
\varepsilon_{v}^{c}=\left(\varepsilon_{1}+2 \varepsilon_{2}\right)-\frac{1-2 v}{E}\left(\sigma_{1}+2 \sigma_{3}\right)
$$

Based on the characteristic stress-strain curves and equation (3), the characteristic stress during the thawing process of the Cretaceous frozen sandstone can be obtained as shown in Table 2.

As shown in Table 2, as the temperature decreased, the closure level of the saturated sandstone gradually decreased, and the crack initiation and expansion levels gradually increased. Considering the macroscopic performance, as the temperature decreased, the compaction phase decreased, the elastic phase increased, and the plastic phase decreased, as shown in Figure 6.
As shown in Figure 8, during the thawing process, as the temperature increased from $-20^{\circ} \mathrm{C}$ to $-4^{\circ} \mathrm{C}$, the peak intensity varied by approximately $35 \%$; as the temperature increased from $-4^{\circ} \mathrm{C}$ to $-2^{\circ} \mathrm{C}$, the peak intensity varied by approximately $50 \%$; as the temperature increased from $-2^{\circ} \mathrm{C}$ to $20^{\circ} \mathrm{C}$, the peak intensity varied by approximately $35 \%$. The other characteristic stresses exhibited similar variation trends. The frozen wall remains in a thawing state for a certain duration after the excavation of the vertical shaft is complete. As shown in Figure 8 and Table 2, as the temperature increases, the intensity gradually decreases. In particular, when the temperature increased from $-4^{\circ} \mathrm{C}$ to $-2^{\circ} \mathrm{C}$, the intensity decreased significantly. Therefore, while monitoring a 


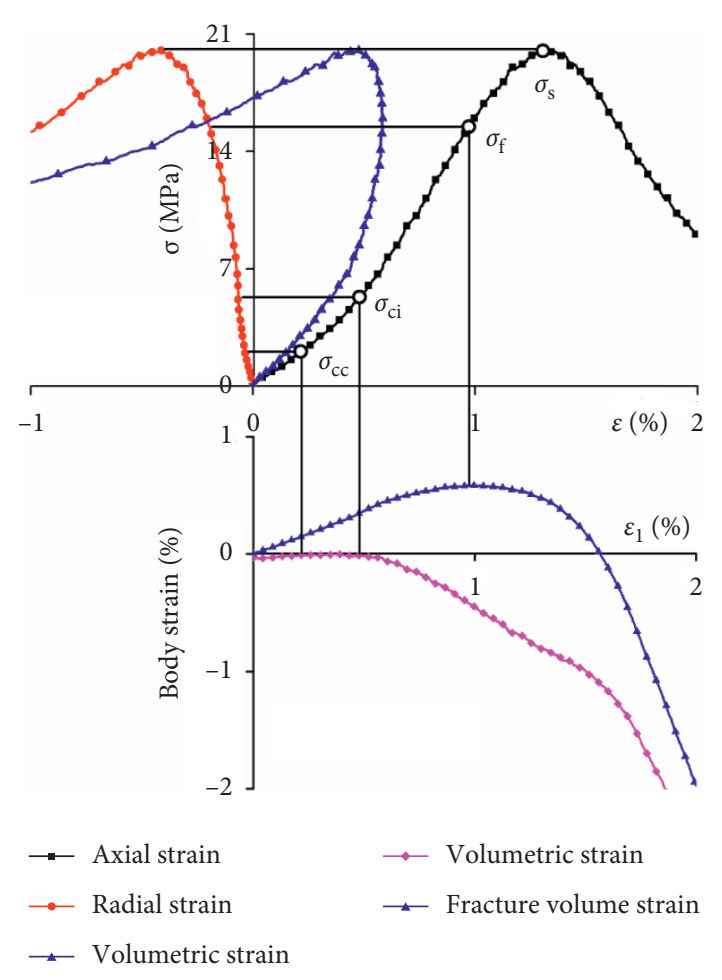

FIGURE 7: Characteristic stress-strain curves of sandstone.

TABLE 2: Strength parameters of Cretaceous frozen sandstone during thawing.

\begin{tabular}{lccccccc}
\hline $\begin{array}{l}T \\
\left({ }^{\circ} \mathrm{C}\right)\end{array}$ & $\begin{array}{c}\sigma_{\mathrm{cc}} \\
(\mathrm{MPa})\end{array}$ & $\begin{array}{c}\sigma_{\mathrm{ci}} \\
(\mathrm{MPa})\end{array}$ & $\begin{array}{c}\sigma_{\mathrm{f}} \\
(\mathrm{MPa})\end{array}$ & $\begin{array}{c}\sigma_{\mathrm{s}} \\
(\mathrm{MPa})\end{array}$ & $\begin{array}{c}\sigma_{\mathrm{cc}} l \\
\sigma_{\mathrm{s}}\end{array}$ & $\begin{array}{c}\sigma_{\mathrm{ci}} / \\
\sigma_{\mathrm{s}}\end{array}$ & $\begin{array}{c}\sigma_{\mathrm{f}} / \\
\sigma_{\mathrm{s}}\end{array}$ \\
\hline 20 & 1.59 & 3.96 & 6.70 & 8.81 & 0.18 & 0.45 & 0.76 \\
0 & 1.89 & 4.83 & 7.99 & 10.51 & 0.18 & 0.46 & 0.76 \\
-2 & 2.28 & 6.03 & 10.33 & 13.40 & 0.17 & 0.45 & 0.77 \\
-4 & 3.41 & 9.22 & 15.64 & 20.05 & 0.17 & 0.46 & 0.78 \\
-6 & 3.87 & 10.93 & 18.00 & 22.78 & 0.17 & 0.48 & 0.79 \\
-10 & 4.06 & 12.44 & 20.31 & 25.39 & 0.16 & 0.49 & 0.80 \\
-20 & 4.71 & 15.39 & 25.44 & 31.41 & 0.15 & 0.49 & 0.81 \\
\hline
\end{tabular}

frozen wall, special attention should be paid to the deformation of the surrounding rock at approximately $-4^{\circ} \mathrm{C}$.

3.3. Acoustic Emission Characteristics. When rock fails and becomes unstable, strain energy is released in the form of elastic waves, resulting in an $\mathrm{AE}$. $\mathrm{AE}$ signals are closely related to the closure of the primary fissures and the propagation and penetration of new cracks in the rock. Therefore, the AE signal can reflect the extent of damage and destruction in the rock under different stress states. Herein, the $\mathrm{AE}$ ringing count was used to reflect the accompanying phenomenon of $\mathrm{AE}$ during the destruction of frozen sandstone. According to the change characteristics of the $\mathrm{AE}$ signal of frozen sandstone fracture during each period, the entire $\mathrm{AE}$ change process can be divided into five stages: (I) quiet period, (II) growth period, (III) frequent period, (IV) sharp increase period, and (V) decline period, as shown in Figure 9.
3.3.1. Quiet Period. During the quiet period, the AE signal changes smoothly, and the signal value is small. The proportion of this period is the smallest, accounting for approximately $0.21 \%-0.54 \%$ of the entire process. As the temperature increases, the overall trend also increases. During this stage, the stress is relatively small, and the original microcracks in the sandstone slowly begin to close under the action of the external load. As the temperature increases, the volume of unfrozen water gradually increases, and the gaps between the particle skeletons and the pore ice increase. Considering the macroscopic performance, the brittleness of the rock decreases and the plasticity increases, which corresponds to the compaction stage of the uniaxial compression test.

3.3.2. Frequent Period. During the frequent period, the AE signal continues to increase, and the signal value also increases. The proportion of this period is higher than that of the previous period, accounting for approximately $4.74 \%-$ $12.78 \%$ of the entire process. As the temperature increases, the overall trend decreases. This period corresponds to the crack propagation stage of the uniaxial compression test. As the load increases, the original cracks are destroyed under the action of the shear stress, and new cracks are generated. During this stage, the cracks inside the rock continue to develop, and the $\mathrm{AE}$ signal tends to be active, with frequent sudden increases.

3.3.3. Sharp Increase Period. During the sharp increase period, the AE signal increases significantly, and the signal value also increases. The proportion of this period is the highest, accounting for approximately $55.41 \%-59.31 \%$ of the entire process. This period corresponds to the plastic yielding stage of the uniaxial compression test. As the load increases, the cracks inside the rock specimen develop fully, and the AE signal exhibits a dramatic increase.

3.3.4. Growth Period. During the growth period, the AE signal slowly increases, and the signal value also increases. The proportion of this period is higher than that of the quiet period, accounting for approximately $2.23 \%-9.11 \%$ of the entire process. As the temperature increases, the overall trend decreases. The growth phase corresponds to the linear elastic phase of the uniaxial compression test. As the load increases, the original cracks begin to propagate in the sandstone. During this stage, the expansion speed is stable, and the stress-strain curve is approximately a straight line. As the temperature increases, the brittleness of the rock decreases, and the plasticity increases. Therefore, the proportion decreases.

3.3.5. Decline Period. During the decline period, the AE signal decreases significantly, and the signal value weakens. The proportion of this period is lower than that of the sharp increase period, accounting for approximately $20.23 \%-$ $35.76 \%$ of the entire process. As the temperature increases, the overall trend also increases. The decline period 


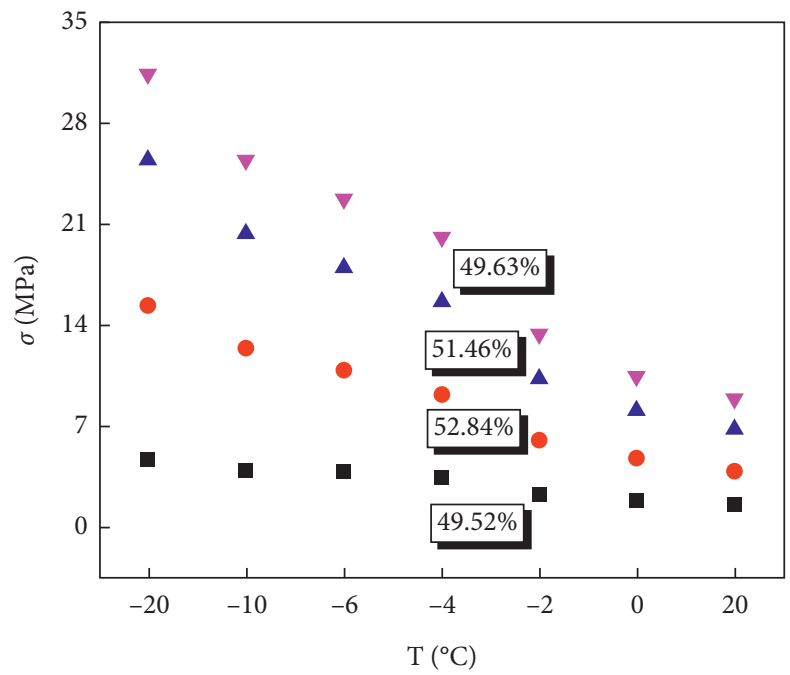

- Closure stress

- Initiation stress

- Expansion stress

$\nabla$ Peak stress

FIGURE 8: Relationship between characteristic stress and temperature of frozen sandstone during thawing.

$t(\mathrm{~s})$

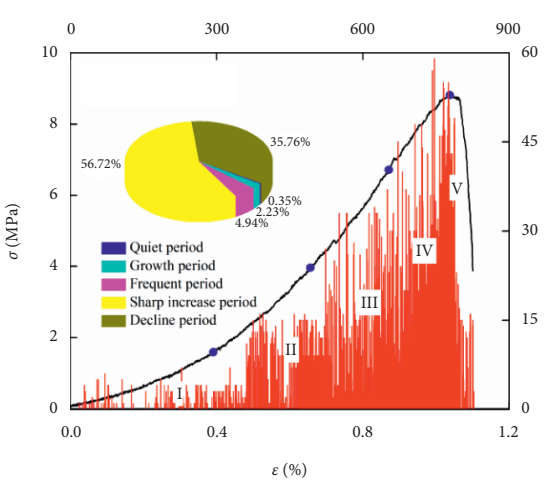

$20^{\circ} \mathrm{C}$

Ring count

- stress-strain curve

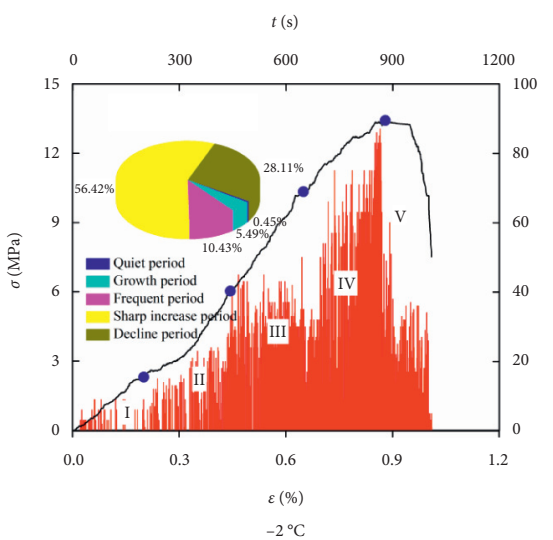

Ring count

-

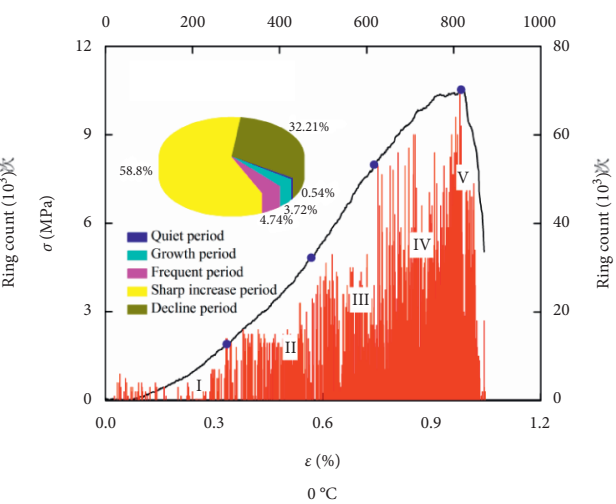

Ring count ___ stress-strain curve

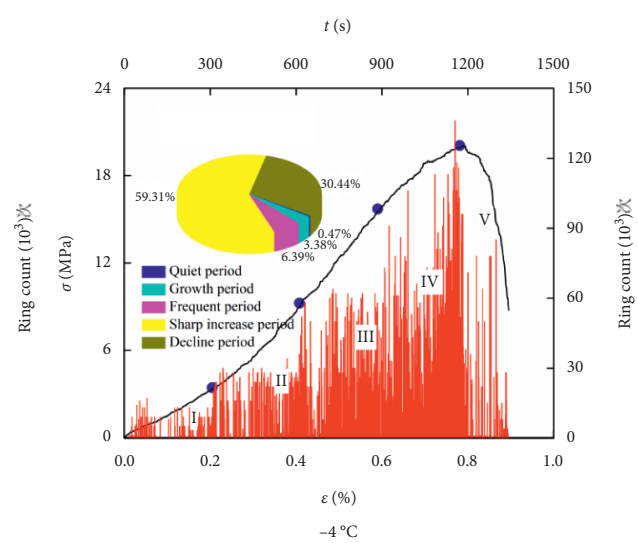

Ring count

_ stress-strain curve

(a)

Figure 9: Continued. 

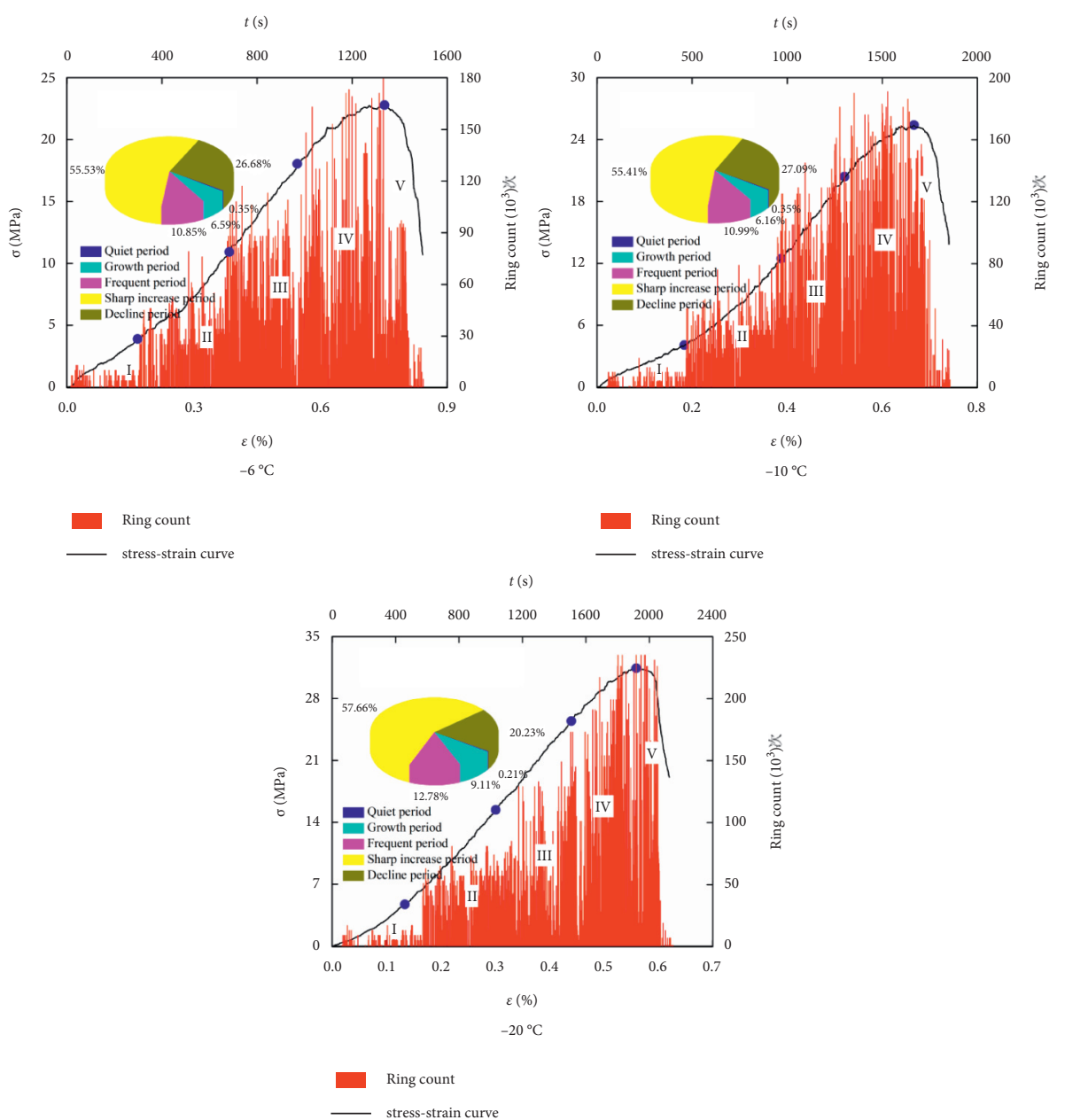

(b)

Figure 9: Relationship between acoustic emission ringing count and time.

corresponds to the postpeak stage of the uniaxial compression test. After the load reaches its peak value, the rock quickly loses stability and breaks down, and the $\mathrm{AE}$ signal drops rapidly. Owing to the low strength of Cretaceous sandstone, which is a water-rich soft rock, the stress drops rapidly during the postpeak stage. However, the increase in strain is higher than that of some hard rocks. During this stage, the AE signal is denser, and the proportion is relatively high.

The five periods of the changes in the AE signal during the thawing of the frozen sandstone and the five stages of the uniaxial compression test are mutually corresponding. As the temperature rises, the $\mathrm{AE}$ signal during the quiet period and the sharp increase period changes smoothly and is not obvious. The AE signal changes significantly during the growth period and the frequent period. As the frozen sandstone is in the linear elastic stage and the crack propagation stage, respectively, during these periods, the temperature has a stronger influence on the brittleness and plasticity of the rock, and the rock is in the critical stage of the brittle-plastic transition. Therefore, the AE signal changes significantly with the increase in temperature during these two stages. As the temperature increases, the plasticity of the rock increases, and the brittleness of the rock decreases. After the load reaches its peak stress, the strain increment is relatively large. The rock becomes unstable and damaged, and the AE signal is relatively dense. Therefore, during the decline period, the proportion of the $\mathrm{AE}$ signal increases as the temperature increases.

\section{Damage Modeling}

4.1. Rock Damage Model. When saturated red sandstone is subjected to low temperatures, ice forms in the water-rich layers, producing a frost heaving force that squeezes the surrounding solid media, expanding the original pores and initiating the development of new fractures, thereby intensifying the internal damage of the rock.

According to the strain equivalence principle proposed by Lemaitre $[16,20]$, the constitutive relationship of rock damage is 


$$
[\sigma]=\left[\sigma^{*}\right](1-D)=[E][\varepsilon](1-D),
$$

where $[\sigma]$ is the nominal stress matrix, $\left[\sigma^{*}\right]$ is the effective stress matrix, $[E]$ is the strain matrix, $[\varepsilon]$ is the elastic matrix, and $D$ is the damage variable.

The failure of the internal unit of the rock has a certain degree of uncertainty. Assuming that the failure of the rock microelement obeys the Weibull distribution, the probability density function can be expressed as

$$
P(x)=\frac{m}{F_{0}} \cdot\left(\frac{F^{*}}{F_{0}}\right)^{m-1} \cdot \exp \left[-\left(\frac{F^{*}}{F_{0}}\right)^{m}\right],
$$

where $F^{*}$ is a random variable whose microelement destruction obeys the Weibull distribution and $F_{0}$ and $m$ are the parameters of the Weibull function that are related to the properties of the rock sample.

Assuming that the rock failure obeys the D-P criterion, the distribution variable can be expressed as

$$
\begin{aligned}
F^{*} & =\alpha I_{1}+\sqrt{J_{2}}, \\
I_{1} & =\sigma_{1}+\sigma_{2}+\sigma_{3}=\frac{\sigma_{m}}{3}, \\
J_{2} & =\frac{1}{6}\left[\left(\sigma_{1}-\sigma_{2}\right)^{2}+\left(\sigma_{2}-\sigma_{3}\right)^{2}+\left(\sigma_{3}-\sigma_{1}\right)^{2}\right], \\
\alpha & =\frac{2 \sin \phi}{\sqrt{3}(3-\sin \phi)} .
\end{aligned}
$$

The damage variable $D$ can be expressed as

$$
D=\int_{0}^{F} P(F) d F=1-\exp \left[-\left(\frac{F^{*}}{F_{0}}\right)^{m}\right] .
$$

Therefore, the constitutive model of rock damage is

$$
\sigma=E \varepsilon \cdot \exp \left[-\left(E \mathcal{\varepsilon} \frac{\sqrt{3} \alpha+1}{\sqrt{3} F_{0}}\right)^{m}\right] .
$$

4.2. Parameter Determination. There are two parameters in the constitutive model, and the parameter values can be determined by using the substitution method. Based on the stress-strain relationship at the peak point, the following geometric conditions are satisfied:

$$
\begin{cases}\varepsilon=\varepsilon_{S} & \sigma=\sigma_{S}, \\ \varepsilon=\varepsilon_{S} & \frac{\partial \sigma_{S}}{\partial \varepsilon_{S}}=0 .\end{cases}
$$

Substituting equation (9) into equation (8), we obtain

$$
\left\{\begin{array}{l}
\sigma_{S}=E \varepsilon_{S} \cdot \exp \left[-\left(E \varepsilon_{S} \frac{\sqrt{3} \alpha+1}{\sqrt{3} F_{0}}\right)^{m}\right] \\
\frac{\partial \sigma_{S}}{\partial \varepsilon_{S}}=\left[E-E \varepsilon_{S} \cdot m \cdot\left(E \varepsilon_{S} \frac{\sqrt{3} \alpha+1}{\sqrt{3} F_{0}}\right)^{m-1} \cdot E \frac{\sqrt{3} \alpha+1}{\sqrt{3} F_{0}}\right] \cdot \exp \left[-\left(E \varepsilon_{S} \frac{\sqrt{3} \alpha+1}{\sqrt{3} F_{0}}\right)^{m}\right]=0 .
\end{array}\right.
$$

The material parameters of the rock can be determined as shown in Table 3.

The parameters $m$ and $F_{0}$ are closely related to the rock damage. To verify the applicability of the proposed frozen rock damage model and the rationality of the parameters, $m$ and $F_{0}$ were first substituted into equation (7) to verify the accuracy of the parameters for the damage variables, as shown in Figure 10. During the loading process, the rock undergoes damage weakening, stable development, and accelerated expansion, and the variables tend to be 1 , which corresponds to the rock compaction stage, linear elastic stage, crack propagation stage, plastic deformation stage, and strain-softening stage. As the temperature increases, the speed of the rock damage also increases. Therefore, the parameters determined using equation (10) are suitable for modeling the damage characteristics of the
Cretaceous frozen sandstone, which conform to the general law.

4.3. Model Verification. To verify the feasibility of the model, the parameter values listed in Table 3 were substituted into equation (8), and the theoretical values were compared with the experimental values, as shown in Figure 11. The comparison demonstrated that the damage model can simulate the stress-strain curves of frozen rock during the thawing process reasonably well. In particular, the linear elastic phase, plastic yield phase, and postpeak phase are highly correlated. However, the theoretical value of the rock strength was slightly smaller than the experimental value. This is because only the overall bearing capacity of the frozen sandstone was considered while establishing the model, and 
TABLE 3: Model parameter values.

\begin{tabular}{lccccccc}
\hline $\begin{array}{l}T\left({ }^{\circ} \mathrm{C}\right) \\
\text { parameter }\end{array}$ & -20 & -10 & -6 & -4 & -2 & 0 & 20 \\
\hline$F_{0}$ & 5.635 & 6.268 & 7.496 & 8.974 & 9.377 & 10.416 & 11.065 \\
$M$ & 6.057 & 6.843 & 7.514 & 8.142 & 8.541 & 8.958 & 9.734 \\
\hline
\end{tabular}

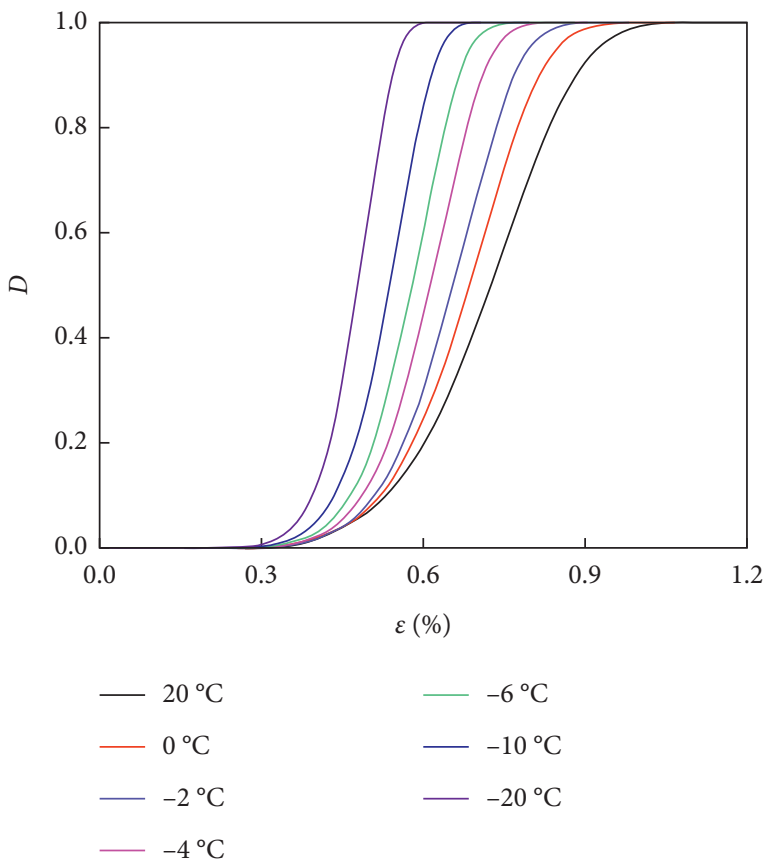

Figure 10: Damage evolution curves.
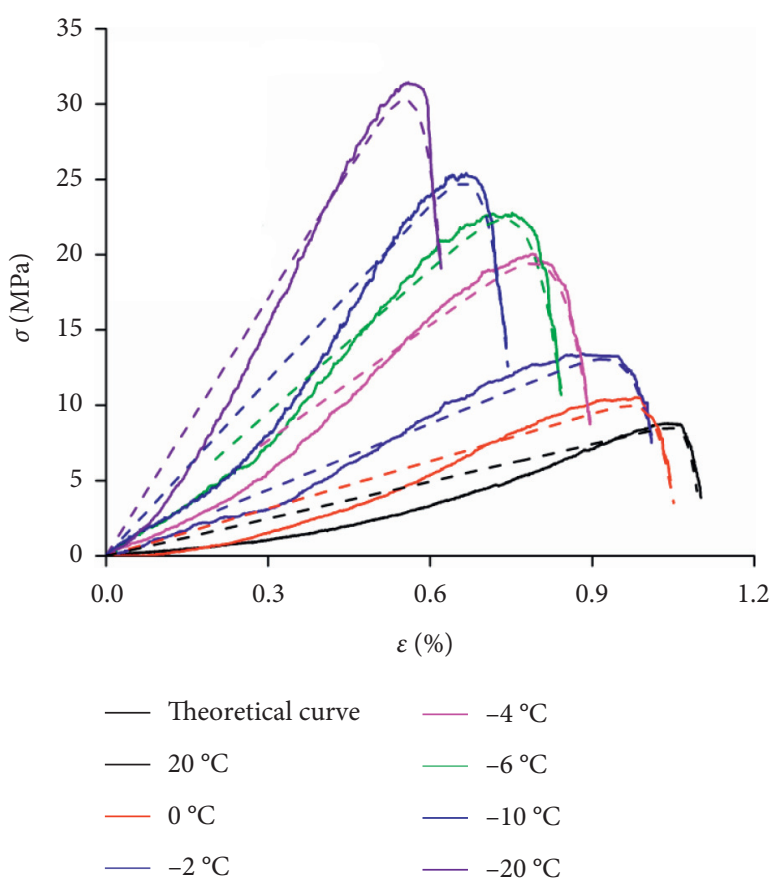

Figure 11: Model verification. the interaction between the solid rock particles and the pore ice was ignored.

\section{Conclusion}

(1) The thawing process of frozen sandstone comprises five stages: the compaction stage, linear elastic stage, crack propagation stage, plastic yield stage, and postpeak stage. As the temperature increases, the compaction stage becomes increasingly obvious. The closure stress, crack initiation stress, expansion stress, and peak strength of the frozen sandstone during the thawing process were obtained from the volumetric stress-strain curve. These values act as the boundary points of the above five stages.

(2) During the thawing process, the characteristic stress of the saturated sandstone exhibited the same variation trend. As the temperature increased, the strength gradually decreased. The level of closure gradually increased, and the levels of initiation and expansion gradually decreased. Macroscopically, as the temperature increased, the compaction stage became increasingly obvious, the elastic stage decreased, and the plastic stage increased.

(3) Synchronous monitoring of the rock during the thawing process can be achieved using the AE technology. Based on the closure stress, crack initiation stress, expansion intensity, and peak intensity of the frozen sandstone during the thawing process, the $\mathrm{AE}$ data can be divided into five periods: the quiet period, growth period, frequent period, sharp increase period, and decline period. As the temperature increased, the brittleness decreased, and the plasticity of the frozen sandstone increased. The AE signals during the quiet and steep increase periods had a small variation range. In contrast, the variations in the AE during the growth, frequent, and decline periods were more obvious.

(4) During the thawing process of saturated sandstone, when the temperature increases to $-4^{\circ} \mathrm{C}$, the strength of the rock undergoes abrupt changes and decreases significantly. Therefore, while monitoring the wall thawing process, special attention must be paid when the temperature is around $-4^{\circ} \mathrm{C}$ to ensure the longterm stability of the freezing wall.

(5) A damage constitutive model of Cretaceous sandstone was established based on the D-P criterion of rock failure. The model was verified using experimental data, and the correlation between the experimental and theoretical data was good. Therefore, compared with normal temperature conditions, the principle of strain equivalence is also applicable to the failure of frozen sandstone during thawing.

\section{Data Availability}

No external data were used for this study, and all the data used in this study are included within the article. The data can be obtained from the author upon request. 


\section{Conflicts of Interest}

The authors declare that they have no conflicts of interest.

\section{Acknowledgments}

This work was supported by the National Natural Science Foundation of China (Grant no. 51774231).

\section{References}

[1] F. Wang, B. Jiang, S. Chen, and M. Ren, "Surface collapse control under thick unconsolidated layers by backfilling strip mining in coal mines," International Journal of Rock Mechanics and Mining Sciences, vol. 113, pp. 268-277, 2019.

[2] K. Xia, C. Chen, Y. Zheng et al., "Engineering geology and ground collapse mechanism in the Chengchao Iron-ore Mine in China," Engineering Geology, vol. 249, pp. 129-147, 2019.

[3] H. Kang, J. Lou, F. Gao, J. Yang, and J. Li, "A physical and numerical investigation of sudden massive roof collapse during longwall coal retreat mining," International Journal of Coal Geology, vol. 188, pp. 25-36, 2018.

[4] Z. Y. Li, G. S. Yang, and Y. Wei, "Construction of frozen sandstone creep damage model and analysis of influencing factors based on fractional-order theory," Arabian Journal for Science and Engineering, 2021.

[5] Q. Liu, W. Chen, J. K. Guo et al., "Fractional stress relaxation model of rock freeze-thaw damage," Advances in Materials Science and Engineering, 2021.

[6] Z. Li, G. Yang, and H. Liu, "The influence of regional freezethaw cycles on loess landslides: analysis of strength deterioration of loess with changes in pore structure," Water, vol. 12, no. 11, p. 3047, 2020.

[7] K. Xing, Z. Zhou, H. Yang, and B. Liu, "Macro-meso freezethaw damage mechanism of soil-rock mixtures with different rock contents," International Journal of Pavement Engineering, vol. 21, no. 1, pp. 9-19, 2020.

[8] Z. Li and G. Yang, "Constitutive model of frozen red sandstone based on ice-solid binary medium," Arabian Journal of Geosciences, vol. 14, no. 16, p. 1616, 2021.

[9] E. Kolay, "Modeling the effect of freezing and thawing for sedimentary rocks," Environmental Earth Sciences, vol. 75, no. 3, p. 210, 2016.

[10] Z. Y. Li, G. S. Yang, and Y. Wei, "Study on creep mechanical properties of frozen cretaceous sandstone during thawing process," Chinese Journal of Rock Mechanics and Engineering, vol. 40, no. 09, pp. 1777-1788, 2021.

[11] Y. S. Kang, C. C. Hou, B. Liu, and Q. S. Liu, "Frost deformation and a quasi-elastic-plastic-creep constitutive model for isotropic freezing rock," International Journal of Geomechanics, vol. 20, no. 8, 2020.

[12] S. B. Huang, Q. S. Liu, Y. Z. Liu, and Z. Y. Ye, "Freezing strain model for estimating the unfrozen water content of saturated rock under low temperature," International Journal of Geomechanics, vol. 18, no. 2, 2018.

[13] Z. L. Chen, P. Wu, Q. Yu, and G. Xu, "Effects of freezing and thawing cycle on mechanical properties and stability of soft rock slope," Advances in Materials Science and Engineering, 2017.

[14] X. Luo, N. Jiang, X. Fan, N. Mei, and H. Luo, "Effects of freezethaw on the determination and application of parameters of slope rock mass in cold regions," Cold Regions Science and Technology, vol. 110, pp. 32-37, 2015.
[15] J.-q. Mu, X.-j. Pei, R.-q. Huang, N. Rengers, and X.-q. Zou, "Degradation characteristics of shear strength of joints in three rock types due to cyclic freezing and thawing," Cold Regions Science and Technology, vol. 138, pp. 91-97, 2017.

[16] H. Zhang, C. Yuan, G. Yang et al., "A novel constitutive modelling approach measured under simulated freeze-thaw cycles for the rock failure," Engineering with Computers, vol. 37, no. 1, pp. 779-792, 2019.

[17] Z. Zhou, Z.-z. Liu, H. Yang, W.-y. Gao, and C.-c. Zhang, "Freeze-thaw damage mechanism of elastic modulus of soil-rock mixtures at different confining pressures," Journal of Central South University, vol. 27, no. 2, pp. 554-565, 2020.

[18] S. B. Huang, Z. X. Lu, Z. Y. Ye, and Z. K. Xin, “An elastoplastic model of frost deformation for the porous rock under freezethaw," Engineering Geology Series, vol. 278, 2020.

[19] L. P. Wang, N. Li, J. L. Qi, Y. Z. Tian, and S. H. Xu, "A study on the physical index change and triaxial compression test of intact hard rock subjected to freeze-thaw cycles," Cold Regions Science and Technology, vol. 160, pp. 39-47, 2019.

[20] H. Liu, G. S. Yang, and Y. H. Yun, "Investigation of sandstone mesostructure damage caused by freeze-thaw cycles via CT image enhancement technology," Advances in Civil Engineering, 2020.

[21] X. P. Zhou and C. Q. Li, "Permeability prediction of porous geomaterials subjected to freeze-thaw cycles based on 3D reconstruction technology," Cold Regions Science and Technology, vol. 181, 2021.

[22] C. J. Liu, D. G. Wang, Z. X. Wang, B. Ke, P. Li, and S. T. Yu, "Dynamic splitting tensile test of granite under freeze-thaw weathering," Soil Dynamics and Earthquake Engineering, vol. 140, 2021.

[23] B. H. Jiang, K. Li, and J. Jin, "The variation characteristics of micro-pore structures of underground rocks in cold regions subject to freezing and thawing cycles," Arabian Journal of Geosciences, vol. 13, no. 17, 2020.

[24] H. Jiang, K. Li, and J. Jin, "The variation characteristics of micro-pore structures of underground rocks in cold regions subject to freezing and thawing cycles," Arabian Journal of Geosciences, vol. 13, no. 1, p. 17, 2020.

[25] G. Mainali, S. Dineva, and E. Nordlund, "Experimental study on debonding of shotcrete with acoustic emission during freezing and thawing cycle," Cold Regions Science and Technology, vol. 111, pp. 1-12, 2015.

[26] X. H. Ni, X. M. Shen, and Z. D. Zhu, "Mechanical and acoustic emission characteristics of sandstone through triaxial unloading test after cyclic freezing-thawing treatment," Advances in Civil Engineering, 2020.

[27] B. Liu, Y. Ma, G. Zhang, and W. Xu, "Acoustic emission investigation of hydraulic and mechanical characteristics of muddy sandstone experienced one freeze-thaw cycle," Cold Regions Science and Technology, vol. 151, pp. 335-344, 2018.

[28] L. X. Chen, K. S. Li, G. L. Song, D. Zhang, and C. X. Liu, "Effect of freeze-thaw cycle on physical and mechanical properties and damage characteristics of sandstone," Sci RepUk, vol. 11, no. 1, 2021.

[29] Y. Wang, C. H. Li, H. Liu, and J. Q. Han, "Fracture failure analysis of freeze-thawed granite containing natural fracture under uniaxial multi-level cyclic loads," Theoretical and Applied Fracture Mechanics, vol. 110, 2020. 